\title{
Importance of daptomycin dosage on the clinical outcomes in early post-liver transplant recipients with vancomycin-resistant enterococci infection
}

Ing-Kit Lee

Chang Gung Memorial Hospital

Yi-Ping Sng

Chang Gung Memorial Hospital

Wei-Feng Li

Chang Gung Memorial Hospital

Chao-Long Chen

Chang Gung Memorial Hospital

Chih-Chi Wang ( $\nabla$ ufel4996@ms26.hinet.net)

Chang Gung Memorial Hospital Kaohsiung Branch

Chih-Che Lin

Chang Gung Memorial Hospital

I-Ling Chen

Chang Gung Memorial Hospital

Research article

Keywords: Liver transplant, vancomycin-resistant enterococci, daptomycin, mortality

Posted Date: March 22nd, 2021

DOl: https://doi.org/10.21203/rs.3.rs-284680/v1

License: (9) (i) This work is licensed under a Creative Commons Attribution 4.0 International License.

Read Full License 


\section{Abstract}

Background: The prevalence of vancomycin-resistant enterococci (VRE) is increasing among liver transplant recipients. This study aimed to explore the clinical features of liver transplant recipients with VRE infection/colonization and to determine the impact of daptomycin dosage on the outcomes.

Methods: We retrospectively enrolled pre-transplant and post-transplant patients with VRE colonization/infection from 2016 to 2019.

Results: Altogether, 428 patients underwent liver transplantation. Among these, 22 (5.1\%) patients developed VRE colonization/infection. All VRE isolates were Enterococcus faecium. Two (9\%) patients acquired VRE in the pre-transplant period, 16 (3 colonizations and 13 infections) $(72.7 \%)$ in the early postliver transplant period ( $\leq 60$-day after transplantation), and 4 ( 2 colonization and 2 infections) $(18.1 \%)$ in the late post-liver transplant period (>6-month after transplantation). Among 13 patients with early postliver transplant VRE infection, 12 (92.3\%) underwent living-donor liver transplantation and 1 underwent deceased donor liver transplantation. Among these 13 patients, the median time from transplant to emergence of VRE infection was 12 days. The median interval from VRE infection to death was 27 days and the 30 -day mortality was $67 \%$. Of these 13 patients, eleven patients (8 survived; 3 died) received daptomycin therapy for VRE. Among them, $4(36.3 \%)$ received daptomycin doses $<8 \mathrm{mg} / \mathrm{kg}$. Nonsurvivors $(n=3)$ received significantly lower daptomycin dose than survivors $(n=8)(P=0.040)$. Daptomycin doses $<8 \mathrm{mg} / \mathrm{kg}$ were more frequently associated with non-survivors $(n=3)$ than with survivors $(n=8)$ $(P=0.024)$.

Conclusions: In summary, the suboptimal dosage of daptomycin may have contributed to a higher rate of in-hospital mortality. Doses $\geq 8 \mathrm{mg} / \mathrm{kg}$ may be needed to adequately treat VRE infection in early post-liver transplant recipients.

Level of evidence: Level III

\section{Introduction}

Although enterococci are constituents of the normal bacterial flora of the lower gastrointestinal tract in humans, they have become one of the most common causes of healthcare-associated infections in the intensive care unit setting and in immunocompromised patients [1,2]. Enterococcus faecalis and Enterococcus faecium contribute to most of the enterococcal infections. These species exhibit decreased susceptibility to ampicillin as well as resistance to vancomycin [2,3]. Vancomycin-resistant enterococci (VRE) were first described in 1986 [4]and their prevalence has rapidly increased globally over the past decades especially among Enterococcus faecium, in which $80 \%-95 \%$ of isolates are vancomycinresistant $[5,6]$.

VRE infection/colonization has been linked to prolonged length of hospitalization, higher costs of hospitalization, and increased mortality in hospitalized patients $[7,8]$. Notably, poor outcomes have been 
reported among liver transplant recipients with VRE infection [9-12]. McNeil et al. revealed that the 90-day mortality was significantly higher among those who developed VRE infection after liver transplantation [9]. In addition, patients with VRE infection had worse graft survival than those without VRE infection [1012]. Treatment options for VRE are limited. Linezolid or daptomycin is recommended for the treatment of VRE [13]. Myelosuppression is one of the major adverse events associated with linezolid [14].

Daptomycin is being used increasingly for the treatment of VRE, particularly in patients with cirrhosis $[15,16]$. However, data regarding the use of daptomycin for the treatment of VRE in liver transplant recipients is inadequate. Most of the previous studies have focused on the impact of daptomycin dosing for treatment of VRE infection in the general population and little is known regarding the optimal dosage of daptomycin for the treatment of VRE in liver transplant recipients. The aim of the present study was to explore the clinical features and outcomes in liver transplant recipients with VRE infection and to determine the effect of daptomycin dosage on the clinical outcomes.

\section{Patients And Methods}

\section{Hospital setting and patients}

This study was conducted at Kaohsiung Chang Gung Memorial Hospital, a 2700-bed primary care and tertiary referral medical center in Taiwan and a leading liver transplantation center in Asia [17]. We retrospectively enrolled pre-liver transplant and post-liver transplant patients admitted to liver transplant surgical intensive care unit with VRE colonization/infection from January 2016 to December 2019. If a patient had multiple episodes of VRE infection or colonization during the study period, only the first episode was included. A standardized form for clinical data collection was designed. Patients' electronic medical records were reviewed to verify the information regarding demographic characteristics, pretransplant and post-transplant clinical characteristics, laboratory and microbiological tests, and outcomes. Patients who developed VRE infection/colonization during the first 60 days after liver transplantation were assigned to the early post-liver transplant colonization/infection group. Patients who acquired VRE infection/colonization at 6 months after liver transplantation was assigned to the late post-liver transplant colonization/infection group.

\section{Antimicrobial susceptibility testing}

Enterococcus spp. were identified using the Phoenix (BD Diagnostic Systems, Sparks, MD, USA) identification system in the clinical microbiology laboratory. Vancomycin resistance was defined as an enterococcus isolate with minimum inhibitory concentration of vancomycin $\geq 32 \mathrm{mg} / \mathrm{L}$. The VRE isolates were considered daptomycin sensitive if they had a minimum inhibitory concentration $\leq 4 \mathrm{mg} / \mathrm{L}$ according to the Clinical and Laboratory Standards Institute [18]. The choice of antibiotic (daptomycin, linezolid, or tigecycline) for VRE infection was based on physicians' judgment. Daptomycin dose was selected by the attending physicians and the dose was calculated according to the actual body weight.

\section{Statistical analysis}


Patients were divided into three groups: the pre-liver transplant group, the early post-liver transplant group, and the late post-liver transplant group. Continuous variables were presented as median and range. Categorical variables were presented as percentages. To analyze the impact of VRE infection among patients in the early post-liver transplant group, we compared demographic, clinical, surgical, and laboratory characteristics as well as daptomycin dosage of survivors and non-survivors using Fisher's exact test for categorical variables and Mann-Whitney $\mathrm{U}$ test for numerical variables. The differences were considered statistically significant at $P<0.05$. Data were analyzed using IBM SPSS Statistics version 19.0 (IBM Corp., Armonk, NY, USA).

\section{Results}

\section{Patients characteristics}

Altogether, 428 patients who underwent liver transplantation were identified during the study period. Among them, 22 (5.1\%) patients (median age: 60.5 years [range: $1-67$ years]) who developed VRE colonization/infection were included in the analysis. All patients with VRE colonization/infection had undergone transplant for the first time. Twenty patients underwent living-donor liver transplantation and 2 underwent transplantation from deceased donors. The three leading comorbidities were hepatocellular carcinoma (40.9\%), hepatitis B infection (36.4\%), and hepatitis C infection (36.4\%). Among the 22 patients with VRE colonization/infection, 2 (9\%) patients acquired VRE in the pre-transplant period, 16 (72.7\%) in the early post-liver transplant period, and 4 (18.1\%) in the late post-liver transplant period. VRE colonization was observed in 3 patients in the early post-liver transplant period and in 2 patients in the late post-liver transplant period. VRE bacteremia developed in $6(27.3 \%)$ patients. Two patients acquired VRE infection while they were on the waiting list for a liver transplant. However, none of them developed VRE infection after transplantation. Four out of 22 patients died, including 3 deaths in the early post-liver transplant period and 1 death in the late post-liver transplant period, resulting in a mortality rate of $18.2 \%$ (Table 1).

\section{Clinical characteristics of patients with VRE infection in the early post-liver transplant period}

Thirteen (median age: 62 years [range: 1-67 years]) patients had VRE infection during the first 60 days following transplantation. All VRE isolates were Enterococcus faecium. Among these patients, 1 patient experienced vancomycin-susceptible Enterococcus faecium bacteremia before liver transplantation. Hepatocellular carcinoma (46.2\%) and hepatitis B infection (46.2\%) were the most common underlying liver conditions followed by hepatitis $\mathrm{C}$ infection (30.8\%) and alcoholic liver cirrhosis (15.4\%). Seven (53.8\%) patients were categorized as Child-Pugh class C. The median Model for End-stage Liver Disease score at transplant was 15.5 (range: 9-32). Twelve (92.3\%) patients underwent living-donor liver transplantation and 1 patient underwent deceased donor liver transplantation. Seven (61.5\%) patients required surgical re-exploration due to biliary stricture (3 patients), bleeding (2 patients), wound dehiscence (1 patient), or portal vein thrombosis (1 patient). Primary graft failure was observed in 4 (30.8\%) patients. Glycopeptides (vancomycin or teicoplanin) and third or fourth generation 
cephalosporins were commonly used prior to the diagnosis of VRE infection. The median time from transplant to emergence of VRE infection was 12 (range: 1-59) days. Most of the VRE were isolated from abdominal (e.g., ascites, bile, and vein graft) $(76.9 \%)$ and blood (30.8\%) specimens. Coinfections with other bacteria in ascites were found in $6(46 \%)$ patients, which included Staphylococcus hemolyticus in 4 (67\%) patients and Klebsiella pneumoniae and Stenotrophomonas maltophilia in one patient each (16.6\%). Delayed VRE treatment ( $\geqq 48$ hours after infection) was noted in $12(92.3 \%)$ patients. The VRE isolates were universally susceptible to daptomycin, linezolid, and tigecycline. Eleven patients received daptomycin therapy for VRE. Among them, 4 (36.3\%) received daptomycin doses $<8 \mathrm{mg} / \mathrm{kg}$. Three patients died, accounting for $23 \%$ of overall in-hospital mortality. The characteristics of the 13 patients with VRE infection in the early post-liver transplant period are summarized in Tables 2 and 3.

\section{Comparison between survivors and non-survivors with VRE infection in the early post-liver transplant period}

In the 3 non-survivors, the median interval from VRE infection to death was 27 (range: 22-32) days and the 30-day mortality after VRE infection was $67 \%$. Among 11 patients received daptomycin therapy for VRE, the non-survivors $(n=3)$ received significantly lower daptomycin dosages than survivors $(n=8)$ (median $7.8 \mathrm{mg} / \mathrm{kg}$ vs. $8.7 \mathrm{mg} / \mathrm{kg}, \mathrm{P}=0.040$ ). Daptomycin dosage $<8 \mathrm{mg} / \mathrm{kg}$ were associated more frequently with non-survivors $(n=3)$ than with survivors $(n=8)(100 \%$ vs. $12.5 \%, P=0.024)$. The frequency of VRE bacteremia and primary graft failure was higher in non-survivors $(n=3)$ than in survivors $(n=10)$ ( $67 \%$ vs. $20 \%$ and $67 \%$ vs. $10 \%$, respectively). However, these differences were not statistically significant. There were no statistically significant differences between survivors $(n=10)$ and non-survivors $(n=3)$ in demographic characteristics, underlying conditions, pre-transplant factors, surgical factors, post-operative complications, and delayed antibiotic therapy for VRE (Tables 2 and 3 ).

\section{Discussion}

VRE have emerged as important nosocomial pathogens in bloodstream, urinary tract, and wound infections over the past 2 decades and will remain so for the foreseeable future [19]. Importantly, immunocompromised patients appear to be at high risk for VRE colonization or infection and show poor prognosis $[20,21]$. The present study described the clinical features and outcomes of liver transplant recipients with VRE infection in detail. Association of an inadequate dose of daptomycin with death was a key finding from the study. Our findings are consistent with those reported in previous series [9-12]. These findings may help solidify our understanding of the clinical features of VRE infection among liver transplant recipients.

Vancomycin resistance is independently associated with increased mortality among patients with enterococcal bloodstream infections [22]. Importantly, an overall in-hospital mortality rate of $18.2 \%$ was observed among all included liver transplant recipients with VRE colonization or infection in the present study. For subjects who developed VRE infection in the early post-liver transplant period, their in-hospital mortality rate increased to $23 \%$. Moreover, $15 \%$ of these patients died within 30 days after development of 
VRE infection. Previous studies have indicated that the crude mortality rate of VRE infection among liver transplant recipients ranged from $23 \%$ to $82 \%$ [9,10,12,22-24]. Excluding the data from an era before the availability of effective antibiotic treatment for VRE infection, the observed mortality rates for VRE bacteremia are still unacceptably high in this patient population (33\% to $56 \%$ ) $[10,25]$. Some previous studies and our report indicate that VRE infection in liver transplant recipients serves as an indicator for is associated with increased mortality. Thus, implementation of appropriate preventive strategies and timely identification of VRE infection in these patients is vital to avoid preventable mortality and morbidity.

Appropriate antimicrobial therapy is crucial in reducing the mortality in patients with VRE infection. Limited effective antimicrobial agents are available to treat VRE infection [26]. Linezolid and daptomycin as are the two most commonly used agents for treatment of VRE infection [13]. Linezolid is a bacteriostatic antibiotic that is approved for the use in VRE infection [13]. Safety concerns limit the use of linezolid, particularly in cirrhotic patients with thrombocytopenia [27]. Additionally, a study including 644 patients with VRE bacteremia noted that treatment with linezolid was associated with significantly higher treatment failure when compared with daptomycin [15]. Daptomycin is a concentration-dependent bactericidal agent. It has been shown to exert rapid bactericidal activity against enterococci [28]. Daptomycin dosage for staphylococcal bacteremia is $6 \mathrm{mg} / \mathrm{kg}$ intravenously once daily [29]. Many clinicians are using similar doses of daptomycin for treatment of VRE infection. In the setting of enterococcal bloodstream infections, Britt et al. revealed that high-dose daptomycin ( $\geq 10 \mathrm{mg} / \mathrm{kg}$ ) was associated with reduced 30-day mortality when compared with the standard-dose (6 mg/kg) [16]. In a study involving 112 patients, Chuang et al. reported that daptomycin regimens with higher doses ( $\geq 9$ $\mathrm{mg} / \mathrm{kg}$ ) were associated with lower mortality than those with standard ( $<7 \mathrm{mg} / \mathrm{kg}$ ) doses [30]. Nonetheless, most of these studies have presented data regarding daptomycin therapeutic dosages for VRE infection in the general patient population rather than in liver transplant patients. We found an association between higher daptomycin dose and survival in liver transplant recipients with VRE infection. Daptomycin dose $\geq 8 \mathrm{mg} / \mathrm{kg}$ was associated with significantly better patient survival than a dose $<8 \mathrm{mg} / \mathrm{kg}$. Survivors received higher median daptomycin dose than non-survivors $(8.7 \mathrm{mg} / \mathrm{kg}$ vs. 7.8 $\mathrm{mg} / \mathrm{kg}$ ). The present study expands the previous findings about the importance of daptomycin therapeutic dosage for the treatment of VRE infection in liver transplant patients. To the best of our knowledge, this is the first study that reported the impact of daptomycin dosage for treatment of VRE infection in liver transplant recipients. Our findings highlight the urgent need for clinicians' awareness regarding optimal daptomycin dosage for the treatment of VRE infection in liver transplant recipients.

Although enterococci are less virulent than many other bacteria, delayed antibiotic therapy for patients with VRE infection is associated with poor clinical outcomes [31]. In the present study, delays in initiating the antimicrobial therapy against VRE did not contribute significantly to increased mortality. Remarkably, only 1 patient in our study received effective antimicrobial therapy within 48 hours after the onset of VRE infection. This finding should be considered with caution while interpreting the data, as it may lead to bias in the results of the present study. Larger prospective studies are required to elucidate whether the delay in the treatment of VRE infection affects the outcome in liver transplant recipients. 
Data regarding the influence of VRE infection on clinical endpoints other than mortality are lacking. We observed that two-thirds of the non-survivors in the early post-transplant period developed VRE bloodstream infection and primary graft failure. The association between VRE bacteremia and primary graft failure is unclear. Multiple factors have been studied as risk factors for graft failure including optimum donor selection; vascular, biliary, and immunological complications; and bacterial infection $[32,33]$. We agree with the suggestions from other studies that VRE infection may have contributed to graft failure in liver transplant recipients [10-12]. On the other hand, the greater number of graft failure in non-surviving patients in this study can be partly explained by the poor general condition including relatively higher Model for End-stage Liver Disease scores at the time of transplantation compared to survivors, although this difference did not reach statistical significance (Table 2).

Pre-transplant VRE colonization or infection could contribute to a higher incidence of VRE infection at the time of organ transplantation. In a prospective surveillance study involving 22 patients with VRE colonization before liver transplantation, 7 (32\%) developed clinical VRE infection post-transplantation [9]. In a study of 61 patients who underwent pre-transplant VRE surveillance, $44 \%$ of the patients exhibited VRE colonization after liver transplantation [34]. In the present study, 2 patients experienced VRE infection prior to the transplantation. Notably, none of them had VRE colonization or infection after transplantation. Additionally, 13 patients developed VRE infection within 60 days after liver transplantation, but none of them had a history of VRE colonization prior to the transplantation. This finding is inconsistent with previously published findings that suggested that VRE colonization in patients was associated with post-transplant VRE infection. The possible explanation for this discrepancy could be that the number of events in our study were not high enough to detect the effect of pre-transplant colonization on post-transplant infection. Additionally, in the present study, the incidence of VRE colonization/infection was $5.1 \%$ among patients admitted to liver transplant surgical intensive care unit, which is lower compared to findings in earlier studies from other countries [23,34]. Although hospital-wide routine active surveillance for VRE was not performed at our institution, poorer outcomes associated with acquisition of VRE infection after transplantation in our study and in earlier reports highlight the importance of infection-control measures including contact precautions, usage of personal protective equipment, and appropriate disinfection strategies to prevent nosocomial acquisition of VRE, especially in the post-transplantation period.

The present study has several limitations. This was a retrospective study and suffered from the limitations of this design. The statistical power was quite low due to the small number of cases studied. Due to the limited sample size, we could not compare the treatment outcomes between daptomycin and linezolid in liver transplant recipients.

\section{Conclusions}

In this study, we observed that VRE infection in liver transplant recipients was associated with poor clinical outcomes. Suboptimal dosages of daptomycin may have contributed to the higher in-hospital mortality rate. Doses greater than or equal to $8 \mathrm{mg} / \mathrm{kg}$ may be needed to adequately treat VRE infection in 
early post-liver transplant recipients. Although larger studies including controlled clinical trials are needed to ensure the efficacy and the safety of daptomycin dosages $\geq 8 \mathrm{mg} / \mathrm{kg}$ in liver transplant recipients, our study highlighted the importance of optimal daptomycin dosages for the treatment of VRE infection.

\section{Abbreviation}

VRE: vancomycin-resistant enterococci

\section{Declarations}

\section{Acknowledgement}

Not applicable.

\section{Authors' contributions}

CCW conceived of the study, and participated in its design and coordination. IKL interpretation of data, performed the statistical analysis, and draft the manuscript. YPS collect the data, assisted in the preparation of the manuscript, and reviewed the manuscript. WFL, CLC, CCL and ILC provided critical appraisal of the manuscript. All authors read and approved the final version of the manuscript.

\section{Funding}

This study received no funding.

\section{Data availability}

All data generated or analyzed during this study are included in this published article.

\section{Ethics approval and consent to participate}

The Institutional Review Board of Kaohsiung Chang Gung Memorial Hospital approved the study (document no.: 202000991B0). The committee waived the requirement for informed consent. All methods were performed in accordance with the relevant guidelines and regulations.

\section{Consent for publication}

Not applicable.

\section{Competing interests}

The authors declare that they have no competing interests.

\section{References}


1. Weiner LM, Webb AK, Limbago B, Dudeck MA, Patel J, Kallen AJ, et al. Antimicrobial-resistant pathogens associated with healthcare-associated infections: Summary of data reported to the National Healthcare Safety Network at the Centers for Disease Control and Prevention, 2011-2014. Infect Control Hosp Epidemiol. 2016;37:1288-1301. https://doi.org/10.1017/ice.2016.174.

2. Arias CA, Murray BE. The rise of the Enterococcus: beyond vancomycin resistance. Nat Rev Microbiol. 2012;10:266-78. https://doi.org/10.1038/nrmicro2761.

3. Noskin GA, Peterson LR, Warren JR. Enterococcus faecium and Enterococcus faecalis bacteremia: acquisition and outcome. Clin Infect Dis. 1995;20:296-301. https://doi.org/10.1093/clinids/20.2.296.

4. Leclercq R, Derlot E, Duval J, Courvalin P. Plasmid-mediated resistance to vancomycin and teicoplanin in Enterococcus faecium. N Engl J Med. 1988;319:157-61. https://doi.org/10.1056/NEJM198807213190307.

5. Ramsey AM, Zilberberg MD. Secular trends of hospitalization with vancomycin resistant Enterococcus infection in the United States, 2000-2006. Infect Control Hosp Epidemiol. 2009;30:184-6. https://doi.org/10.1086/593956.

6. Arias CA, Mendes RE, Stilwell MG, Jones RN, Murray BE. Unmet needs and prospects for oritavancin in the management of vancomycin-resistant enterococcal infections. Clin Infect Dis. 2012;54(suppl 3):S233-8. https://doi.org/10.1093/cid/cir924.

7. Butler AM, Olsen MA, Merz LR, Guth RM, Woeltje KF, Camins BC, et al. Attributable costs of enterococcal bloodstream infections in a nonsurgical hospital cohort. Infect Control Hosp Epidemiol. 2011;31:28-35. https://doi.org/10.1086/649020.

8. Song X, Srinivasan A, Plau D, Perl T. Effect of nosocomial vancomycin resistant enterococcal bacteremia on mortality, length of stay, and costs. Infect Control Hosp Epidemiol. 2003;24:251-6. https://doi.org/10.1086/502196.

9. McNeil SA, Malani PN, Chenoweth CE, Fontana RJ, Magee JC, Punch JD, et al. Vancomycin-resistant enterococcal colonization and infection in liver transplant candidates and recipients: a prospective surveillance study. Clin Infect Dis. 2006;42:195-203. https://doi.org/10.1086/498903.

10. Kim YJ, Jun YH, Choi HJ, You YK, Kim DG, Choi JY, et al. Impact of enterococcal bacteremia in liver transplant recipients. Transplant Proc. 2019;51:2766-70. https://doi.org/10.1016/j.transproceed.2019.02.064.

11. Ziakas PD, Pliakos EE, Zervou FN, Knol BM, Rice LB, Mylonakis E. MRSA and VRE colonization in solid organ transplantation: a meta-analysis of published studies. Am J Transplant. 2014;14:188794. https://doi.org/10.1111/ajt.1278.

12. Gearhart M, Martin J, Rudich S, Thomas M, Wetzel D, Solomkin J, et al. Consequences of vancomycin-resistant enterococcus in liver transplant recipients: a matched control study. Clin Transplant. 2005;19:711-6. https://doi.org/10.1111/j.1399-0012.2005.00362.x.

13. Wang JL, Hsueh PR. Therapeutic options for infections due to vancomycin-resistant enterococci. Expert Opin Pharmacother. 2009;10:785-96. https://doi.org/10.1517/14656560902811811. 
14. Green SL, Maddox JC, Huttenbach ED. Linezolid and reversible myelosuppression. JAMA. 2001;285:1291. https://doi.org/10.1001/jama.285.10.1291.

15. Britt NS, Potter EM, Patel N, Steed ME. Comparison of the effectiveness and safety of linezolid and daptomycin in vancomycin-resistant enterococcal bloodstream infection: a national cohort study of Veterans Affairs patients. Clin Infect Dis. 2015;61:871-8. https://doi.org/10.1093/cid/civ444.

16. Britt NS, Potter EM, Patel N, Steed ME. Comparative effectiveness and safety of standard-, medium-, and high-dose daptomycin strategies for the treatment of vancomycin-resistant enterococcal bacteremia among veterans affairs patients. Clin Infect Dis. 2017;64:605-13. https://doi.org/10.1093/cid/ciw815.

17. Chen $\mathrm{CL}$, Kabiling CS, Concejero AM. Why does living donor liver transplantation flourish in Asia? Nat Rev Gastroenterol Hepatol. 2013;10:746-51. https://doi.org/10.1038/nrgastro.2013.194.

18. Clinical and Laboratory Standards Institute. Performance standards for antimicrobial susceptibility testing: 20th informational supplement, M100-S20. Wayne, PA: CLSI;2010.

19. Prematunge $C$, MacDougall C, Johnstone J, Adomako K, Lam F, Robertson J, et al. VRE and VSE bacteremia outcomes in the era of effective VRE therapy: a systematic review and meta-analysis. Infect Control Hosp Epidemiol. 2016;37:26-35. https://doi.org/10.1017/ice.2015.228.

20. Bossaer JB, Hall PD, Garrett-Mayer E. Incidence of vancomycin resistant enterococci (VRE) infection in high-risk febrile neutropenic patients colonized with VRE. Support Care Cancer. 2010;19:231-7. https://doi.org/10.1007/s00520-009-0808-y.

21. Peel T, Cheng AC, Spelman T, Huysmans M, Spelman D. Differing risk factors for vancomycinresistant and vancomycin-sensitive enterococcal bacteraemia. Clin Microbiol Infect. 2012;18:38894. https://doi.org/10.1111/j.1469-0691.2011.03591.x.

22. DiazGranados CA, Zimmer SM, Klein M, Jernigan JA. Comparison of mortality associated with vancomycin-resistant and vancomycin-susceptible enterococcal bloodstream infections: a metaanalysis. Clin Infect Dis. 2005;41:327-33. https://doi.org/10.1086/430909.

23. Orloff SL, Busch AM, Olyaei AJ, Corless CL, Benner KG, Flora KD, et al. Vancomycin-resistant enterococcus in liver transplant patients. Am J Surg. 1999;177:418-22. https://doi.org/10.1016/s0002-9610(99)00083-5.

24. Russell DL, Flood A, Zaroda TE, Acosta C, Riley MM, Busuttil RW, et al. Outcomes of colonization with MRSA and VRE among liver transplant candidates and recipients. Am J Transplant. 2008;8:1737-43. https://doi.org/10.1111/j.1600-6143.2008.02304.x.

25. Kim YJ, Kim SI, Choi JY, Yoon SK, You YK, Kim DG. Clinical significance of methicillin-resistant Staphylococcus aureus and vancomycin-resistant enterococci colonization in liver transplant recipients. Korean J Intern Med. 2015;30:694-704. https://doi.org/10.3904/kjim.2015.30.5.694.

26. Arias CA, Contreras GA, Murray BE. Management of multidrug-resistant enterococcal infections. Clin Microbiol Infect. 2010;16:555-62. https://doi.org/10.1111/j.1469-0691.2010.03214.x.

27. Ikuta S, Tanimura K, Yasui C, Aihara T, Yoshie H, lida H, et al. Chronic liver disease increases the risk of linezolid-related thrombocytopenia in methicillin-resistant Staphylococcus aureus-infected 
patients after digestive surgery. $\mathrm{J}$ Infect Chemother. 2011;17:388-91.

https://doi.org/10.1007/s10156-010-0188-8.

28. Whang DW, Miller LG, Partain NM, McKinnell JA. Systematic review and meta-analysis of linezolid and daptomycin for treatment of vancomycin-resistant enterococcal bloodstream infections. Antimicrob Agents Chemother. 2013;57:5013-8. https://doi.org/10.1128/AAC.00714-13.

29. Fowler VG Jr, Boucher HW, Corey GR, Abrutyn E, Karchmer AW, Rupp ME, et al. Daptomycin versus standard therapy for bacteremia and endocarditis caused by Staphylococcus aur N Engl J Med. 2006;355:653-65. https://doi.org/10.1056/NEJMoa053783.

30. Chuang YC, Lin HY, Chen PY, Lin CY, Wang JT, Chen YC, et al. Effect of daptomycin dose on the outcome of vancomycin-resistant, daptomycin-susceptible Enterococcus faecium Clin Infect Dis. 2017;64:1026-34. https://doi.org/10.1093/cid/cix024.

31. Zasowski EJ, Claeys KC, Lagnf AM, Davis SL, Rybak MJ. Time Is of the Essence: The impact of delayed antibiotic therapy on patient outcomes in hospital-onset enterococcal bloodstream infections. Clin Infect Dis. 2016;62:1242-50. https://doi.org/10.1093/cid/ciw110.

32. Varotti G, Grazi GL, Vetrone G, Ercolani G, Cescon M, Del Gaudio M, et al. Causes of early acute graft failure after liver transplantation: analysis of a 17-year single-centre experience. Clin Transplant. 2005;19:492-500. https://doi.org/10.1111/j.1399-0012.2005.00373.x.

33. Wagener G, Raffel B, Young AT, Minhaz M, Emond J. Predicting early allograft failure and mortality after liver transplantation: the role of the postoperative model for end-stage liver disease score. Liver Transpl. 2013;19:534-42. https://doi.org/10.1002/It.23634.

34. Banach DB, Peaper DR, Fortune BE, Emre S, Dembry LM. The clinical and molecular epidemiology of pre-transplant vancomycin-resistant enterococci colonization among liver transplant recipients. Clin Transplant. 2016;30:306-11. https://doi.org/10.1111/ctr.12690.

\section{Table}

Table 1 Characteristic of 22 liver transplantation patients with vancomycin-resistant enterococci infection 


\begin{tabular}{|c|c|}
\hline Variable & $N=22$ \\
\hline Median age (range), years & $60.5(1-67)$ \\
\hline Male & $12(54.5)$ \\
\hline \multicolumn{2}{|l|}{ Underlying conditions } \\
\hline Hepatitis B & $8(36.4)$ \\
\hline Hepatitis C & $8(36.4)$ \\
\hline Alcoholic liver cirrhosis & $4(18.2)$ \\
\hline Primary biliary cirrhosis & $2(9.1)$ \\
\hline Biliary atresia & $2(9.1)$ \\
\hline Cryptogenic liver disease & $1(4.5)$ \\
\hline Hepatocellular carcinoma & $9(40.9)$ \\
\hline Diabetes mellitus & $3(13.6)$ \\
\hline Hypertension & $5(22.7)$ \\
\hline Chronic kidney disease & $4(18.2)$ \\
\hline \multicolumn{2}{|l|}{ Child-Pugh class } \\
\hline Class A & $1(4.5)$ \\
\hline Class B & $11(50)$ \\
\hline Class C & $10(45.5)$ \\
\hline \multicolumn{2}{|l|}{ Acquisition of VRE colonization/infection } \\
\hline Pre-liver transplant & $2(9.1)$ \\
\hline Early post-liver transplant (<2 months) & $16^{\star}(72.7)$ \\
\hline Late post-liver transplant ( $\geqq 6$ months) & $4^{\dagger}(18.2)$ \\
\hline \multicolumn{2}{|l|}{ Site of VRE infection } \\
\hline Blood & $6(27.3)$ \\
\hline Bile & $2(9.1)$ \\
\hline Ascites & $8(36.4)$ \\
\hline Catheter & $1(4.5)$ \\
\hline Vein graft & $1(4.5)$ \\
\hline Urine & $3(13.6)$ \\
\hline
\end{tabular}


Data were no (\%) unless otherwise indicated

VRE Vancomycin-resistant enterococci

* VRE colonization was found in 3 patients

${ }^{\dagger}$ VRE colonization was found in 2 patients

Table 2 Demographic characteristics and comorbid conditions of 13 patients with vancomycin-resistant enterococcus infection in the early post-liver transplant period. 
Variable

\section{Total}

= 13)
$(N$ Survivors $(N$
$=10$ )

Non-survivors $\mathrm{P}$ $(N=3)$

\section{Demographic feature}

$\begin{array}{lllll}\text { Median age (range), years } & 62(1-67) & 63(1-67) & 62(44-67) & 0.865 \\ \text { Male } & 6(46.2) & 4(40) & 2(67) & 0.599\end{array}$

Underlying conditions

\begin{tabular}{lllll} 
Hepatitis B & $6(46.2)$ & $4(40)$ & $2(67)$ & 0.599 \\
Hepatitis C & $4(30.8)$ & $3(30)$ & $1(33)$ & $>0.99$ \\
Alcoholic liver cirrhosis & $2(15.4)$ & $2(20)$ & 0 & $>0.99$ \\
Primary biliary cirrhosis & $1(7.7)$ & $1(10)$ & 0 & $>0.99$ \\
\hline Biliary atresia & $1(7.7)$ & $1(10)$ & 0 & $>0.99$ \\
\hline Cryptogenic liver disease & $1(7.7)$ & $1(10)$ & 0 & $>0.99$ \\
\hline Hepatocellular carcinoma & $6(46.2)$ & $4(40)$ & $2(67)$ & 0.599 \\
\hline Diabetes mellitus & $1(7.7)$ & $1(10)$ & 0 & $>0.99$ \\
\hline Hypertension & $3(23.1)$ & $3(30)$ & 0 & 0.528 \\
\hline Chronic kidney disease & $2(15.4)$ & $1(10)$ & $1(33)$ & 0.423 \\
\hline Median Child-Pugh scores (range) & $10(7-13)$ & $9(7-13)$ & $10(9-11)$ & 0.488 \\
\hline Child-Pugh class C & & & & $>$ \\
\hline Class A & 0 & 0 & 0 & $1(33)$ \\
\hline Class B & $6(46.1)$ & $5(50)$ & $2(67)$ & $>0.99$ \\
\hline Class C & $7(53.8)$ & $5(50)$ & $23.5(19-28)$ & 0.194 \\
\hline Median MELD score (range) & $15.5(9-32)$ & $15(9-32)$ & & - \\
\hline Pretransplant fag & & & & \\
\hline
\end{tabular}

\section{Pre-transplant factor ( 6 months before} liver transplantation)

\begin{tabular}{lllll} 
Hospitalization history & $9(69.2)$ & $7(70)$ & $2(67)$ & $>0.99$ \\
\hline Stay in intensive care unit history & $5(38.5)$ & $4(40)$ & $1(33)$ & $>0.99$ \\
Receipt of B-lactam antibiotics & $2(15.4)$ & $2(20)$ & 0 & $>0.99$ \\
$\begin{array}{l}\text { Receipt of 3-4th generation } \\
\text { cephalosporins }\end{array}$ & $12(92.3)$ & $9(90)$ & $3(100)$ & $>0.99$ \\
Receipt of quinolones & $3(23.1)$ & $3(30)$ & 0 & 0.528 \\
Receipt of carbepenems & $\begin{array}{l}4(30.8) \\
\text { Page 14/18 }\end{array}$ & $4(40)$ & 0 & 0.497
\end{tabular}


Data are no. (\%) of patients, unless otherwise indicated

MELD Model for End-stage Liver Disease

Table 3 Surgical and clinical characteristics as well as outcomes of 13 patients with vancomycinresistant enterococcus infection in the early post-liver transplant period. 
Variable

\section{Surgical factor}

Median surgery time (range), min

Median anhepatic time (range), min

Median cold ischemic time (range), min

Living donor liver transplant

Cadaver donor liver transplant

Median intraoperative blood loss (range), $\mathrm{ml}$

Median intraoperative transfusion (range), units

Leukocyte-poor packed red cells

Fresh Frozen Plasma

Leukocyte-poor platelet concentrates

Cryoprecipitate

\section{Postoperative factor}

Re-exploration*

$7(53.8)$

Primary graft failure

Biliary stricture

Biliary leak

Venous thrombosis

Graft rejection

Received hemodialysis

Bacteremia before occurring VRE infection

Antibiotics before occurring VRE infection

Receipt of B-lactam antibiotics

Receipt of 3-4th generation cephalosporins

$\begin{array}{ccl}\text { Total } & \text { Survivors } & \text { Non- } \\ (N=13) & (N=10) & \text { survivors } \\ & & (N=3)\end{array}$

$574(440-$

750)

$577(440-$

750)

$522(471-$ 591)

$65.5(33-\quad 71(41-180)$

$57(33-63)$

0.116

180)

$42(24-$

345)

$38(24-70)$

$46(37-$

345)

$12(92.3)$

$10(100)$

$2(67)$

1 (7.7)

0

1 (33)

0.231

4650 (210-

15000)

4675 (210-

10200)

3250 (80015000)
P 


\begin{tabular}{|c|c|c|c|c|}
\hline Receipt of quinolones & $6(46.2)$ & $5(50)$ & $1(33)$ & $>0.99$ \\
\hline Receipt of carbepenems & $8(61.5)$ & $6(60)$ & $2(67)$ & $>0.99$ \\
\hline Receipt of glycopeptides & $11(84.6)$ & $9(90)$ & $3(100)$ & $>0.99$ \\
\hline Receipt of tigecycline & $2(15.4)$ & $1(10)$ & $1(33)$ & 0.423 \\
\hline Receipt of daptomycin & $2(15.4)$ & $1(10)$ & $1(33)$ & 0.423 \\
\hline $\begin{array}{l}\text { Median interval between liver transplant and } \\
\text { development of VRE infection (range), day }\end{array}$ & $12(1-59)$ & $10(1-59)$ & $18(3-57)$ & 0.735 \\
\hline \multicolumn{5}{|l|}{ VRE infection site ${ }^{\dagger}$} \\
\hline Intra-abdominal infection & $10(76.9)$ & $8(80)$ & $2(67)$ & $>0.99$ \\
\hline Bile & $1(7.7)$ & $1(10)$ & 0 & $>0.99$ \\
\hline Ascites & $8(61.5)$ & $6(60)$ & $2(67)$ & $>0.99$ \\
\hline Vein graft & $1(7.7)$ & $1(10)$ & 0 & $>0.99$ \\
\hline Blood & $4(30.8)$ & $2(20)$ & $2(67)$ & 0.203 \\
\hline Catheter & $1(7.7)$ & 0 & $1(33)$ & 0.231 \\
\hline Urine & $1(7.7)$ & $1(10)$ & 0 & $>0.99$ \\
\hline \multicolumn{5}{|l|}{ VRE species } \\
\hline Enterococcus faecium & $13(100)$ & $10(100)$ & $3(100)$ & - \\
\hline Enterococcus faecalis & 0 & 0 & 0 & - \\
\hline Delayed VRE treatment ( $\geqq 48 \mathrm{~h}$ after infection) & $12(92.3)$ & $10(100)$ & $2(67)$ & 0.231 \\
\hline \multicolumn{5}{|l|}{ VRE treatment } \\
\hline Receipt of linezolid & $1(7.7)$ & $1(10)$ & 0 & $>0.99$ \\
\hline Receipt of daptomycin & $11(84.6)$ & $8(80)$ & $3(100)$ & $>0.99$ \\
\hline Receipt of tigecycline & $1(7.7)$ & $1(10)$ & 0 & $>0.99$ \\
\hline Median daptomycin dose (range), $\mathrm{mg} / \mathrm{kg}$ & $\begin{array}{l}8.2(3.5- \\
9.6)(n= \\
11)\end{array}$ & $\begin{array}{l}8.7(4.5- \\
9.6)(n=8)\end{array}$ & $\begin{array}{l}7.8(3.5- \\
7.8)\end{array}$ & 0.040 \\
\hline Daptomycin dose $<8 \mathrm{mg} / \mathrm{kg}$ & $\begin{array}{l}4(36.3)(n \\
=11)\end{array}$ & $\begin{array}{l}1(12.5)(\mathrm{n} \\
=8)\end{array}$ & $3(100)$ & 0.024 \\
\hline Mixed VRE and other bacterial infection & $6(46)$ & $5(50)$ & $1(33)$ & $>0.99$ \\
\hline \multicolumn{5}{|l|}{ Laboratory data at the time of VRE infection } \\
\hline Median white blood cell (range) $\left(10^{9}\right.$ cells $\left./ \mathrm{L}\right)$ & $7.6(2.8-$ & $6.8(2.8-$ & $8.5(4-9)$ & 0.781 \\
\hline
\end{tabular}




\begin{tabular}{|lllll|} 
& $10.6)$ & $10.6)$ & & \\
\hline Median hemoglobin (range) (g/dL) & $8.9(6.6-$ & $9.3(7-10.6)$ & $8.3(6.6-$ & 0.266 \\
\hline Median platelet (range) $\left(10^{9}\right.$ cells/L) & $10.6)$ & & $9.3)$ & \\
\hline Median creatinine (range) (mg/dl) & $73(20-$ & $76(20-343)$ & $70(33-$ & 0.782 \\
& $343)$ & & $110)$ & \\
\hline Median total bilirubin (range) (mg/dL) & $1.0(0.23-$ & $1.0(0.2-$ & $2.3(0.5-$ & 0.221 \\
\hline Median GOT (range) (U/L) & $4.22)$ & $1.6)$ & $4.2)$ & \\
& $5.0(0.7-$ & $3.7(0.74-$ & $26.8(1.8-$ & 0.405 \\
\hline Median GPT (range) (U/L) & $66)$ & $66)$ & $35.4)$ & \\
\hline Median PT (range), INR & $102(27-$ & $84(27-495)$ & $133(39-$ & 0.309 \\
& $2879)$ & & $2879)$ & \\
\hline Median albumin (range) (g/dL) & $60(33-$ & $56(33-462)$ & $64(49-$ & 0.518 \\
\hline Median length of hospital stay (range), day & $1139)$ & & $1139)$ & \\
\hline Outcome & $1.1(1.0-$ & $1.1(1-1.7)$ & $1.7(1.1-$ & 0.052 \\
\hline Died & $2.3)$ & & $2.3)$ & \\
\hline Median interval from VRE infection to death & $3.7(2.8-$ & $3.7(2.8-$ & $3.8(2.9-$ & 0.926 \\
(range), day & $100(44-$ & $118(44-$ & $80(46-$ & 0.310 \\
\hline Mortality at 30 days from VRE infection & $2(15.3)$ & - & $101)$ & \\
\hline
\end{tabular}

Data are no. (\%) of patients, unless otherwise indicated

AST Aspartate Aminotransferase, ALT Alanine aminotransferase, PT Prothrombin time, VRE vancomycinresistant enterococci

*Biliary stricture in 3 patients, bleeding in 2, wound dehiscence in 1, and portal vein thrombosis in 1 ${ }^{\dagger}$ One patient might have more than one site of VRE infection 